\title{
Electronic Sputtering of Solids by Slow, Highly Charged Ions: Fundamentals and Applications
}

T. Schenkel, M.W. Newman, T.R. Niedermayr, G.A. Machicoane, J.W. McDonald, A.V. Barnes, A.V. Hamza, J.C. Banks, B.L. Doyle and K.J. Wu

This paper was prepared for submittal to the

International Conference on Ion Beam Analysis

European Conference on Accelerators in Applied Research and Technology

Dresden, Germany

July 26-30, 1999

July 20, 1999

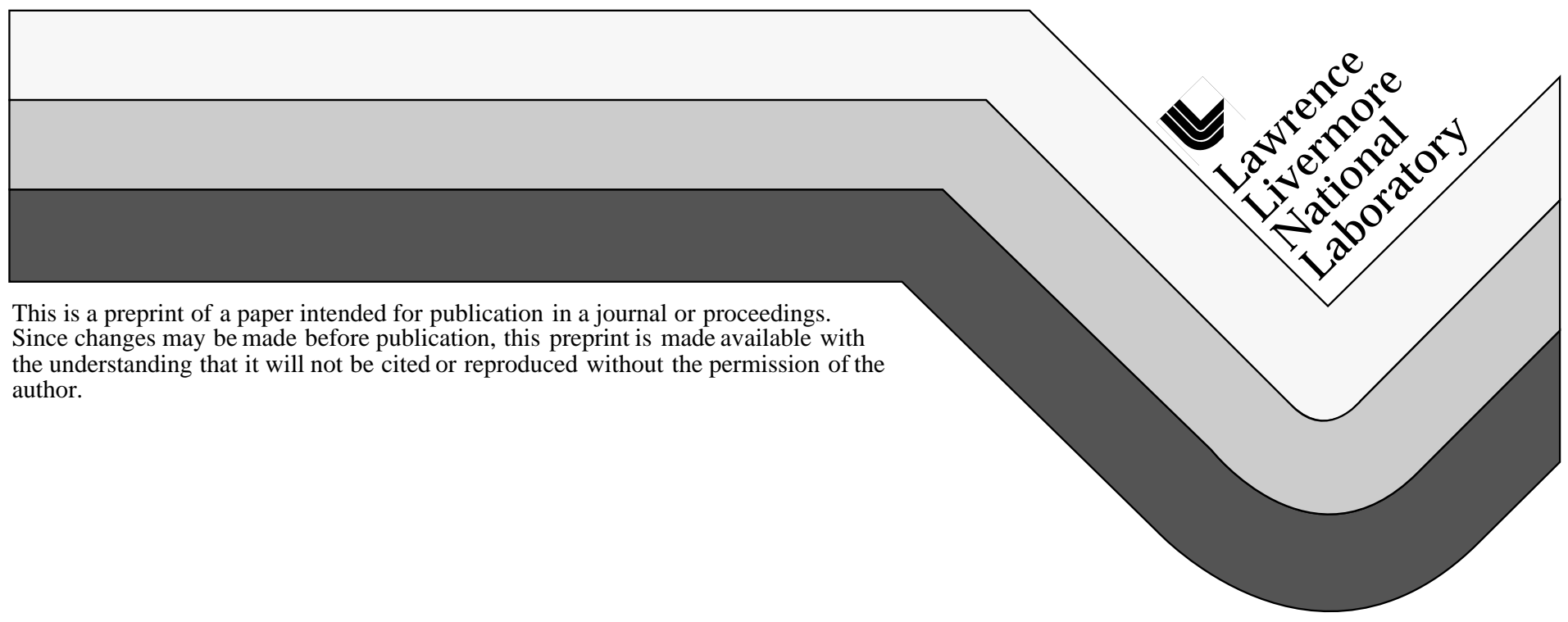




\section{DISCLAIMER}

This document was prepared as an account of work sponsored by an agency of the United States Government. Neither the United States Government nor the University of California nor any of their employees, makes any warranty, express or implied, or assumes any legal liability or responsibility for the accuracy, completeness, or usefulness of any information, apparatus, product, or process

disclosed, or represents that its use would not infringe privately owned rights. Reference herein to any specific commercial product, process, or service by trade name, trademark, manufacturer, or otherwise, does not necessarily constitute or imply its endorsement, recommendation, or favoring by the United States Government or the University of California. The views and opinions of authors expressed herein do not necessarily state or reflect those of the United States Government or the University of California, and shall not be used for advertising or product endorsement purposes. 
UCRL-JC-133729

\title{
Electronic Sputtering of Solids by Slow, Highly Charged Ions: Fundamentals and Applications
}

T. Schenkel, M. W. Newman, T. R. Niedermayr, G. A. Machicoane, J. W. McDonald,

\author{
A. V. Barnes, and A. V. Hamza \\ Lawrence Livermore National Laboratory, Livermore, CA, USA \\ J. C. Banks and B. L. Doyle \\ Sandia National Laboratory, Albuquerque, NM, USA \\ K. J. Wu \\ Charles Evans and Associates, Redwood City, CA, USA
}

Electronic sputtering in the interaction of slow $\left(\mathrm{v}<\mathrm{v}_{\text {Bohr }}\right)$, highly charged ions (SHCI) with solid surfaces have been subject of controversial discussions for almost 20 years. We review results from recent studies of total sputtering yields and discuss distinct microscopic mechanisms (such as defect mediated desorption, Coulomb explosions and effects of intense electronic excitation) in the response of insulators and semiconductors to the impact of SHCI. We then describe an application of ions like $\mathrm{Xe}^{44+}$ and $\mathrm{Au}^{69+}$ as projectiles in time-of-flight secondary ion mass spectrometry for surface characterization of semiconductors.

\section{Introduction}

Continuous development of ion source technology in recent years has made beams of slow $\left(\mathrm{v}<\mathrm{v}_{0}=2.19106 \mathrm{~m} / \mathrm{s}\right)$, highly charged ions (SHCI) available for ion-solid interaction studies [1-3]. It is the defining characteristic of SHCI that their charge state, $q$, is much 
larger than the mean equilibrium charge state which ions develop when traveling in solids with comparable velocities. The latter are about $1+$ for $\mathrm{v}<<\mathrm{v}_{0}$. Consequently, SHCI neutralize and de-excite rapidly when they interact with solid surface. Mean charge equilibration times of SHCI like $\mathrm{Xe}^{44+}$ and $\mathrm{Th}^{75+}$ in thin carbon foils have been found to be only 7 fs [4]. The loss of kinetic energy of ions to target electrons and nuclei is significantly enhanced during charge equilibration $[5,6]$. The potential energy of SHCI, i. e., the sum of the binding energies of the electrons removed from the ion, is dissipated during de-excitation. This potential energy, $51 \mathrm{keV}$ and $198 \mathrm{keV}$ for $\mathrm{Xe}^{44+}$ and $\mathrm{Th}^{75+}$, is deposited initially in a nanometer size target volume close to the surface. The equivalent power density in this process is $\sim 10^{14} \mathrm{~W} / \mathrm{cm}^{2}$. De-excitation begins above surfaces by the resonant capture of target electrons and the formation of a hollow atom. Except for grazing incident collisions, only a small fraction of the potential energy can be dissipated before ions reach the surface, because the available time is too short for relaxation through Auger and radiative transitions. Hollow atom formation and decay in and above metallic and insulating targets has been investigated in great detail by measurements of secondary electron emission, Auger electron and x-ray spectroscopy [1-3]. Atomic force microscopy has been applied to the characterization of nanometer size defects on mica surfaces $[2,7]$ and on self assembled monolayers $[3,8]$ formed by the impact of individual SHCI. SHCI have been found to efficiently develop photo-resist materials such as poly(methymethacrylate) and masked ion beam lithography has been demonstrated for $\mathrm{Xe}^{44+}[9]$.

Insulators, semiconductors and thin semimetals react to the intense, ultrafast electronic excitation imposed by SHCI with the emission of large numbers of secondary 
ions and neutrals. A theory of electronic sputtering by SHCI has to describe microscopic mechanisms for the transfer of projectile potential energy, or electronic excitation energy, into kinetic energy of sputtered particles [10]. Defect mediated sputtering by SHCI up to $\mathrm{Xe}^{27+}$ has been demonstrated for $\mathrm{LiF}$ and $\mathrm{SiO}_{2}[11,12]$. Sputtering by Coulomb explosions $[1,3,10]$ was found to be consistent with results for uranium oxide and SHCI like $\mathrm{Xe}^{44+}$ and $\mathrm{Th}^{70+}[13]$. A third model considers effects of high densities of electronic excitation on the structural stability of solids. This approach can explain the very large sputter yields found for GaAs under impact of $\mathrm{Th}^{70+}$ [14]. In the following, we will discuss some of the experimental challenges in measurements of sputtering yields, before reviewing results on sputter yield measurements in the light of the complementary theories.

The finding of secondary ion intensities in the order of 0.1 to 5 secondary ions detected per SHCI [15] stimulated interest in the development of SHCI based surface analysis in a time-of-flight secondary ion mass spectrometry scheme [16-18]. Secondary ion production was found to be dominated by the projectile charge and largely independent of projectile velocity $[13,15]$. The detection of more than one secondary ion from one impact event with high enough (>0.01) probability allows for the analysis of correlations in secondary ion emission. Since multiple secondary ions are emitted by individual projectiles from an area of only a few tens of $\mathrm{nm}^{2}$, coincidence analysis can deliver information on chemical structure and composition of materials on a nanometer length scale [17]. We will present results on the characterization of sub-micron copper lines and copper particles on $\mathrm{SiO}_{2}$ by this approach in section 4 . 


\section{Experimental techniques for sputter yield measurements}

Two established techniques for the measurement of sputter yields in particle solid interactions are the microbalance and the catcher techniques. The former uses a quartz crystal to monitor the change in resonance frequency associated with the mass change of the irradiated surface as a function exposure time. The sensitivity of this technique has been extended to allow for measurements of mass changes as low as $10^{-3}$ monolayers [1]. While this sensitivity is impressive, application of the microbalance technique for measurement of sputter yields in the order of 10 atoms removed per projectile requires a beam current of a few $\mathrm{nA}$ or about $10^{10}$ projectiles per second. Beam currents of this order are routinely extracted from ECR sources but only for ions with charge states below about $30+$ for xenon.

In the catcher or collector technique, sputtered particles are collected on a secondary target for in situ or ex situ analysis after accumulation of a sufficiently high surface coverage [10, 19]. Recently, Mieskes et al. [20] have reported on in situ analysis of catcher targets in studies of sputtering yields of metals by high energy heavy ions $(\sim 1$ $\mathrm{MeV} / \mathrm{u}$ ). Using a $1.5 \mathrm{MeV}$ carbon beam they were able to detect Ti on Si at coverages in the low $10^{13}$ atoms $/ \mathrm{cm}^{2}$ range.

For the sputter yield measurements with SHCI from the EBIT at Lawrence Livermore National Laboratory, collectors consisted of thin $(50$ to $150 \mathrm{~nm}) \mathrm{SiO}_{2}$ layers on silicon substrates. In order to maximize the collection efficiency, catcher targets were placed at a distance of $6 \mathrm{~mm}$ from the sputter targets, resulting in a view factor of 0.1 . Beams of SHCI at $0.3 \mathrm{v}_{0}$ impinged on GaAs and $\mathrm{UO}_{2}$ targets with an incident angle of $30^{\circ}$. Targets 
were cleaned in situ and surface conditions were monitored by secondary ion mass spectrometry with highly charged projectiles (HCI-SIMS) [3, 13, 14]. Beam intensities for extraction of SHCI from an EBIT are in the order of $10^{6} \mathrm{Xe}^{44+} / \mathrm{s}$ and $10^{5} \mathrm{Au}^{69+} / \mathrm{s}$. At a sputtering yield of 10 atoms per projectile, surface coverages of sputtered materials after exposures of several days are only in the order of $10^{11}$ atoms $/ \mathrm{cm}^{2}$. These low coverages provided excellent samples for sensitivity tests of HCI-SIMS [18]. Quantitative analysis of catcher targets was performed at the heavy ion backscatter facility at Sandia National Laboratory [21] using beams of $100 \mathrm{KeV}$ carbon ions. The sensitivity of HIBS for detection of heavy elements on otherwise clean silicon is in the order of $10^{9}$ atoms $/ \mathrm{cm}^{2}$. In figure 1 we show an example of HIBS analysis of a catcher target $\left(150 \mathrm{~nm} \mathrm{SiO}{ }_{2}\right.$ on $\left.\mathrm{Si}\right)$ with a uranium coverage of $3.3(+/-0.3) \times 10^{11}$ atoms $/ \mathrm{cm}^{2}$.

Relative uncertainties in sputter yields determined with the collector technique result from uncertainties in HIBS results, dose uncertainties, and variations in the view factors between measurements and range typically from $+/-10-30 \%$. One contribution to the systematic error stems from assumptions on sticking probabilities of secondary particles on the catcher surface. Typical values for the latter are $>0.9$ [22]. Another uncertainty lies in the assumption of a cosine angular distribution of secondary particles in the calculation of the view factor. Analysis of catcher targets is a standard technique for determination of actual angular distributions of secondary neutrals [19]. This approach requires a distance between target and collector that is large compared to the spot size of the primary beam. The increased target-collector distance corresponds to a reduction in the achievable surface coverage. With the current beam intensity limitations for SHCI such a reduction of surface coverage was prohibitive in our experiments. 
Overall systematic uncertainties for sputtering yield values determined for SHCI from EBIT with the catcher technique are about $+/-50 \%$.

Secondary ion yields from $\mathrm{GaAs}$ and $\mathrm{UO}_{2}$ samples were measured by time-of-flight secondary ion mass spectrometry with SHCI as projectiles [15-18]. Briefly, SHCI are extracted from EBIT and impinge on samples under normal incidence for analysis in a low resolution, high transmission instrument. Samples are biased to a few thousand volts positive or negative bias and secondary ions are accelerated to an extraction grid and then drift to an annular microchannelplate detector. The detection efficiency of this arrangement is $\sim 0.15$. Time-of-flight cycles are started by secondary electrons or protons that are emitted following the impact of individual projectiles. This single ion triggering scheme allows for a timing resolutions of $1 \mathrm{~ns}$ and a start efficiency of practically $100 \%$ in negative polarity and $>80 \%$ in positive polarity for SHCI like $\mathrm{Xe}^{44+}$. Conventional TOF-SIMS instruments use electronic starts derived from bunched ion pulses and can achieve the nanosecond timing resolution needed for competitive mass resolution [23]. This approach is impractical for SHCI at the currently available beam intensities. For catcher analysis, secondary ions were extracted into a reflectron type time-of-flight spectrometer with a mass resolution, $\mathrm{m} / \Delta \mathrm{m}$, of 1000 at $\mathrm{m}=28 \mathrm{u}[18]$.

\section{Sputter yields: Results and discussion}

Results from sputter yield measurements for CsI [10], $\mathrm{LiF}[11,12], \mathrm{SiO}_{2}$ [12], GaAs $[12,14,24]$ and $\mathrm{UO}_{2}[13]$ are shown in Fig. 2 as a function of potential energy of SHCI [3]. 
The model of defect-mediated desorption can explain sputter yields of several hundred target atoms with the formation and successive decay of electronic defects such as self-trapped excitons and self trapped holes in alkali halides and $\mathrm{SiO}_{2}[11,12]$. The study of CsI by Weathers et al. [10] had shown how efficient electronic excitation energy is transferred to kinetic energy of sputtered particles in materials were such electronic defects can be formed. Here, yields were dominated by electronic energy loss of $60 \mathrm{KeV}$ Ar ions and the increase as a function of projectile charge from $\mathrm{q}=4+$ to $\mathrm{q}=11+$ was small on the background of this offset.

Results for GaAs are most controversial. The absence of yield increases for very slow $\mathrm{Ar}^{\mathrm{q}+}$ up to $8+$ is consistent with the defect-mediated sputtering model since the required defects can not be formed in GaAs $[12,14]$. On the contrary, the finding of increasing ablation rates for $\mathrm{Ar}^{\mathrm{q+}}$ up to 9+ was interpreted in terms of a phenomenological Coulomb explosion model by Mochiji et al. [24]. Results from experiments with highly charged xenon and thorium ions showed a dramatic increase of sputtering yields to a value of $1410+/-210$ atoms $/ \mathrm{Th}^{70+}[14]$. Measurements of secondary ion yields allowed for a determination of the ionization probabilities of secondary ions, and, contrary to expectations from a simple Coulomb explosion model, the ionization probability was found to decrease for very high charge states. The high sputtering yields for GaAs can be understood when considering the structural stability of covalent solids under conditions of intense, ultrafast electronic excitation induced by de-exciting SHCI [3, 14]. This model was developed for the description of femtosecond melting of $\mathrm{Si}$ and GaAs where high densities $\left(>10^{21} \mathrm{~cm}^{-3}\right)$ of electronic excitations were induced by femtosecond lasers [25]. 
For $\mathrm{UO}_{2}$, total yields were also found to increase as a function of potential energy of SHCI, but secondary ion yields were found to increase stronger, resulting in an increase of the ionization probability of positive secondary ions by about an order of magnitude to a value of 5-7\% [13]. Also, spectra of positive secondary ions showed series of uranium oxide clusters, which could be detected up to $\left(\mathrm{UO}_{2}\right)_{7}{ }^{+}$. Relatively high ionization probabilities and significant cluster ion emission are consistent with a coulomb explosion model. However, contributions from defect formation and effects of high excitation densities could also contribute.

Very high secondary ion yields and cluster ion emission has also been observed for $\mathrm{SiO}_{2}$ targets $[15,16]$. For this material all three of the above processes are likely to contribute to sputtering by SHCI [26]. Detailed experimental and theoretical [27] studies are necessary to differentiate contributions from competing mechanisms as a function of excitation intensity.

\section{Applications of HCI-SIMS}

The potential of SHCI like $\mathrm{Xe}^{44+}$ for applications in surface analysis lies in the fact that these ions produce up to three orders of magnitude more secondary ions than singly charged projectiles [3, 9, 13-18, 28, 29].

In HCI-SIMS, each time-of-flight cycle is started by the impact of an individual projectile. Time-of flight secondary ion mass spectrometry (TOF-SIMS) spectra can be taken both in histogram mode or in list mode. In the former, TOF-cycles from consecutive projectiles are simply summed up to form a spectrum. Typically, accumulation of cycles from impact of a few million projectiles yields sufficient statistics 
and accumulation times are about $10 \mathrm{~min}$. In list mode, time-of-flight cycles (i. e., the start trigger and associated stops from secondary ions) from each projectile are stored separately. Then, conditions on the presence of selected mass peaks are selected when TOF-cycles are summed up. The resulting coincidence spectra show correlations between selected secondary ions or molecular ions that were detected. Each projectile forms secondary ions from a surface area with an estimated size of only a few tens of nanometers [8], and the correlations therefore contain considerable information about the local chemical composition.

The probability for the detection of $\mathrm{n}$ secondary ions following the impact of a one $\mathrm{Xe}^{47+}$ projectile $\left(\mathrm{E}_{\mathrm{kin}}=545 \mathrm{keV}\right)$ is shown in Fig. 3. The target was a test wafer with $800 \mathrm{~nm}$ wide copper interconnect lines imbedded in a $25 \mathrm{~nm} \mathrm{TaO}$ diffusion barrier layer in $\mathrm{SiO}_{2}[29,30]$. HCI-SIMS data were taken with the reflectron type analyzer and were accumulated for $1.1 \times 10^{7} \mathrm{Xe}^{47+}$ projectiles. At the given transmission of the reflectron $(\sim 0.1)$, the probability for detection of two secondary ions is $5 \%$. Up to eight secondary ions have been detected from one individual sputtering event. Detection of at least two secondary ions with the observed probabilities makes the analysis of correlations between secondary ions practical.

The correlation coefficient, $\mathrm{C}(\mathrm{A}, \mathrm{B})$, gives a measure for the probability to detect a secondary ion $\mathrm{B}$ in coincidence with ion $\mathrm{A}[17,30,31]$ :

$$
\mathrm{C}(\mathrm{A}, \mathrm{B})=\frac{\mathrm{P}(\mathrm{A}, \mathrm{B})}{\mathrm{P}(\mathrm{A}) \mathrm{P}(\mathrm{B})}
$$

Here, $\mathrm{P}(\mathrm{A})$ and $\mathrm{P}(\mathrm{B})$ are the probabilities for the detection of secondary ions $\mathrm{A}$ and $\mathrm{B}$ independently in all impact events. $\mathrm{P}(\mathrm{A}, \mathrm{B})$ is the probability for detection of $\mathrm{A}$ and $\mathrm{B}$ in the same impact event. For $\mathrm{C}(\mathrm{A}, \mathrm{B})>1$, it is more likely to detect $\mathrm{A}$ when $\mathrm{B}$ is also 
present. An example of correlation coefficients is given in Fig. 4 a) for secondary ions from the copper interconnect sample [30]. The probability to detect a ${ }^{65} \mathrm{Cu}^{+}$is increased when ${ }^{63} \mathrm{Cu}^{+}$was also detected in the impact event. ${ }^{65} \mathrm{Cu}^{+}$and ${ }^{63} \mathrm{Cu}^{+}$are both emitted when a highly charged ions probes an area on one of the copper lines. On the contrary, $\mathrm{C}(\mathrm{A}, \mathrm{B})$ $<1$ indicates an anti-correlation between, e. g. emission of ${ }^{28} \mathrm{Si}^{+}$and ${ }^{65} \mathrm{Cu}^{+}$or ${ }^{63} \mathrm{Cu}_{2}^{+}$. Here, it is very unlikely to detect both a copper and a silicon ion from the same impact event. This anti-correlation is characteristic for well separated structures of different chemical composition. Statistical uncertainties in values of correlation coefficients are typically smaller than $+/-20 \%$.

Detection of $\mathrm{TaO}^{+}$ions from the Ta barrier layer is, at the given level of statistical uncertainly, weakly anti-correlated to both silicon and copper ions. This is expected for a well separated, intact barrier layer and also demonstrates that highly charged ions do indeed probe surface features on a length scale of a few tens of $\mathrm{nm}$.

In contrast, copper ions emitted from a bulk copper sample show no significant correlations (Fig 4b).

In another example of coincidence analysis the sample was a $\mathrm{SiO}_{2}$ wafer which had been coated with $\mathrm{CuSO}_{4}$. The surface coverage of the copper oxide was $\sim 0.03$ monolayers. Fig. 5 shows correlation coefficients with very strong correlations between copper and copper oxide molecular ions. These correlations indicating the presence of well separated copper oxide and silicon dioxide areas on the surface and would not be expected for a blanket deposit of evenly separated copper oxide molecules. The latter is energetically unfavorable and the formation of islands has been studied extensively in the context of the early stages of thin film growth. Fig. 6 shows a section of an HCI-SIMS 
spectrum with positive secondary ions emitted from the $\mathrm{CuSO}_{4} / \mathrm{SiO}_{2}$ sample. The detection of copper oxide clusters is consistent with the presence of copper oxide islands or particles on the surface. Comparison of our results with results from direct imaging techniques [32] is subject of ongoing studies.

\section{Summary}

Data on sputtering yields for the impact of slow, highly charged ions are now available for ions up to $\mathrm{Th}^{70+}$ and for insulators (alkali halides, $\mathrm{SiO}_{2}$ and $\mathrm{UO}_{2}$ ) as well as for one semiconductor (GaAs). Yields in electronic sputtering by SHCI can exceed yields known from linear collision cascade sputtering by orders of magnitude. In comparing results from materials with distinct electronic properties it becomes clear that SHCI induced sputtering is a complex phenomena with contributions from several microscopic mechanisms for the transfer of potential energy of projectiles to kinetic energy of sputtered particles. Defect mediated desorption was demonstrated for alkali halides and $\mathrm{SiO}_{2}$ in a regime of relatively low excitation strength (i. e., for charge states $<30+$ for xenon). Contributions from Coulomb explosions were observed in sputtering and secondary ion production from uranium oxide and for SHCI like $\mathrm{Xe}^{44+}$ and $\mathrm{Th}^{70+}$. High sputtering yields for GaAs (1400 atom/ $\left.\mathrm{Th}^{70+}\right)$ can be understood when considering the effects of intense $\left(1 \mathrm{E} 14 \mathrm{~W} / \mathrm{cm}^{2}\right)$, ultrafast $(7 \mathrm{fs})$ electronic excitations induced by deexciting SHCI. The quantitative differentiation of distinct sputtering mechanisms for different materials and in different regimes of excitation strength is the challenge of continuous studies. 
Detection of multiple secondary ions following the impact of individual SHCI allows for the analysis of correlation effects in secondary ion emission. Since each projectile emits secondaries from an area of a few tens of $\mathrm{nm}^{2}$, coincidence analysis can reveal information on chemical structure and composition on a nanometer length scale and with high sensitivity. The presented examples of coincidence analysis of copper structures on silicon dioxide wafers demonstrate the capabilities of this approach. Ongoing studies concern quantitative comparison of HCI-SIMS with established topographical and chemical analysis techniques.

\section{Acknowledgements}

The authors gratefully acknowledge the excellent technical support at the LLNL EBIT facility provided by D. Nelson and E. Magee. This work was performed under the auspices of the U. S. Department of Energy by Lawrence Livermore National Laboratory under contract No. W-7405-ENG-48. Parts of this work were supported by an SBIR grant from NIST. 


\section{References:}

[1] A. Arnau, F. Aumayr, P. M. Echenique, M. Grether, W. Heiland, J. Limburg, R. Morgenstern, P. Roncin, S. Schipers, R. Schuch, N. Stolterfoht, P. Varga, T. J. M. Zouros, and H. Winter, Surf. Sci. Rep. 27 (1997) 113

[2] D. H. G. Schneider, M. A. Briere, Phys. Scr. 53 (1996) 228

[3] T. Schenkel, A. V. Hamza, A. V. Barnes, and D. H. Schneider, Prog. Surf. Sci., in press

[4] M. Hattass, T. Schenkel, A. V. Hamza, A. V. Barnes, M. W. Newman, J. W. McDonald, T. R. Niedermayr, G. A. Machicoane, and D. H. Schneider, Phys. Rev. Lett. 82, 4795 (1999)

[5] T. Schenkel, M. A. Briere, A. V. Barnes, A. V. Hamza, K. Bethge, H. SchmidtBöcking, and D. Schneider, Physical Review Letters 79, 2030 (1997); T. Schenkel, A. V. Hamza, A. V. Barnes, and D. H. Schneider, Physical Review A 56 R1701 (1997); M. A. Briere, T. Schenkel, D. H. Schneider, P. Bauer, A. Arnau, Phys. Scr. T73, 324 (1997)

[6] J. I. Juaristi, A. Arnau, P. M. Echenique, C. Auth and H. Winter, Phys. Rev. Lett. 82, $1048(1999)$

[7] D. C. Parks, M. P. Stockli, E. W. Bell, L. P. Ratkliff, R. W. Schmieder, F. G. Serpa, and J. P. Gillaspy, Nucl. Instrum. Meth. Phys. Res. B 134, 46 (1998)

[8] T. Schenkel, M. Schneider, M. Hattass, M. W. Newman, A. V. Barnes, A. V. Hamza, and D. H. Schneider, J. Vac. Sci. Technol. B 16, 3298 (1998).

[9] J. D. Gillaspy, D. C. Parks, and L. P. Ratkliff, J. Vac. Sci. Technol. B 16, 3294 (1998) 
[10] D. L. Weathers, T. A. Tombrello, M. H. Prior, R. G. Stokstad, R. E. Tribble, Nuclear Instruments and Methods in Physics Research B 42, 307 (1989)

[11] T. Neidhart, F. Pichler, F. Aumayr, HP. Winter, M. Schmid and P. Varga, Physical Review Letters 74, 5280 (1995); Nuclear Instruments and Methods in Physics Research B 98, 465 (1996)

[12] M. Sporn, G, Libiseller, T. Neidhart, M. Schmid, F. Aumayr, HP. Winter, and P. Varga, Physical Review Letters 79, 945 (1997); P. Varga, T. Neidhard, M. Sporn, G. Libiseller, M. Schmid, F. Aumayr and HP. Winter, Phys. Scr. T73, 307 (1997)

[13] T. Schenkel, A. V. Barnes, A. V. Hamza, J. C. Banks, B. L. Doyle, D. H. Schneider, Physical Review Letters 80, 4325 (1998)

[14] T. Schenkel, A. V. Barnes, A. V. Hamza, J. C. Banks, B. L. Doyle, D. H. Schneider, Physical Review Letters 81, 2590 (1998)

[15] T. Schenkel, A. V. Barnes, M. A. Briere, A. V. Hamza, A. Schach von Wittenau, D, H. Schneider, Nuclear Instruments and Methods in Physics Research B 125, 153 (1997); T. Schenkel et al., Materials Science Forum 248-249, 413 (1997); T. Schenkel et al., Phys. Rev. Lett. 78, 2481 (1997)

[16] T. Schenkel, A. V. Hamza, A. V. Barnes, D. H. Schneider, D. S. Walsh, and B. L. Doyle, Journal of Vacuum Science and Technology A 16 (1998) 1384.

[17] A. V. Hamza, T. Schenkel, A. V. Barnes, and D. H. Schneider, Journal of Vacuum Science and Technology A 17, 303 (1999).

[18] T. Schenkel, A. V. Hamza, A. V. Barnes, M. W. Newman, G. Machicoane, T. Niedermayr, M. Hattass, J. W. McDonald, K. J. Wu, R. W. Odom, and D. H. 
Schneider, Proceedings of the IX International Conference on the Physics of Highly Charged Ions, Bensheim, Physica Scripta, T80, 1999, in press.

[19] H. H. Andersen and H. L. Bay, in Sputtering by Particle Bombardment I, R. Behrisch (ed.) (Springer, Berlin, 1981), P. 145-218

[20] H. D. Mieske, W. Assmann, M. Brodale, M. Dobler, H. Glückler, P. Hartung, and P. Stenzel, Nucl. Instrum. Meth. Phys. Res. B 146, 162 (1998)

[21] J.C. Banks, B. L. Doyle, J. A. Knapp, D. Werho, R. B. Gregory, M. Anthony, T. Q. Hurd, and A. C. Diebold, Nucl. Instr. Methods Phys. Res. B 138, 1223 (1998); J. A Knapp, J. C. Banks, and B. L. Doyle, Nuclear Instruments and Methods in Physics Research B 85, 20 (1994).

[22] K. G. Liebrecht, J. E. Griffith, R. A. Weller, and T. A. Tombrello, Radiat. Eff. 49, $195(1980)$

[23] A. Benninghoven, Angew. Chem. Int. Ed. Engl. 33, 1023 (1994)

[24] K. Mochiji, N. Itabashi, S. Yamamoto, H. Shimizu, S. Ohtani, Y. Kato, H. Tanuma, K. Okuno, N. Kobayashi, Surf. Sci. 357-358, 673 (1996); Jpn. J. Appl. Phys. 34, 6861 (1995)

[25] P. Stampfli, Nuclear Instruments and Methods in Physics Research B 107, 138 (1996); P. Stampfli, K. H. Bennemann, Applied Physics A 60, 191 (1996)

[26] H. Gnaser, Low-Energy Ion irradiation of Solid Surfaces (Springer, Berlin, 1999)

[27] H. P. Cheng, and J. D. Gillaspy, Phys. Rev. B 55, 2628 (1997)

[28] T. Sekioka, M. Terasawa, T. Mitamura, M. P. Stöckli, U. Lehnert, and C. L. Cocke, Nucl. Instr. Methods B 146, 172 (1998) 
[29] H. Li, D. J. Hymes, J. de Larios, I. A. Mowat, and P. M. Lindley, Micro, March 1999, P. 35

[30] T. Schenkel, K. J. Wu, H. Li, M. W. Newman, A. V. Barnes, J. W. McDonald, and A. V. Hamza, Proceedings of the $1^{\text {st }}$ International Conference on Advanced Materials and Processes for Microelectronics, San Jose, March 1999, J. Vac. Sci. Technol. B, in press

[31] E. F. da Silveira, S. B. Duarte and E. A. Schweikert, Surf. Sci. 408, 28 (1998)

[32] A. C. Diebold, P. Lindley, J. Viteralli, J. Kingsley, B. Y. H. Liu, and K.-S. Woo, J. Vac. Sci. Technol. A 16, 1825 (1998) 
Figure captions:

Figure 1.: Heavy ion backscattering spectrum from of a $\mathrm{U}_{-} \mathrm{SiO}_{2}(150 \mathrm{~nm}$ on $\mathrm{Si})$ catcher target (solid) and an unexposed witness target (dashed). Projectiles were carbon at 120 $\mathrm{keV}$. The incident charge was $10 \mu \mathrm{C}$. The uranium coverage was $3.3(+/-0.3) \times 10^{11}$ atoms $/ \mathrm{cm}^{2}$.

Figure 2: Total sputtering yields for CsI, solid squares, [10]; LiF, open circles, [11, 12]; $\mathrm{SiO}_{2}$, solid triangles, [12]; GaAs, solid circles, [12], open diamonds [24], solid diamonds [14]; and $\mathrm{UO}_{2}[13]$ vs. potential energy of projectile. Kinetic energies of projectiles were constant within each data set but varied in measurements by different groups.

Figure 3: Probability, $\mathrm{P}(\mathrm{n})$ for the detection of $\mathrm{n}$ secondary ions following the impact of one $\mathrm{Xe}^{47+}$ ion on $\mathrm{SiO}_{2}$ sample with $800 \mathrm{~nm}$ wide $\mathrm{Cu}$ interconnects.

Figure 4: a) Correlation coefficients from coincidence analysis of secondary ions from a $\mathrm{Cu}$-interconnect sample [29] and b) from a bulk copper target.

Figure 5: Correlation coefficients from coincidence analysis of a $\mathrm{CuSO}_{4} / \mathrm{SiO}_{2}$ sample with a copper oxide coverage of 0.03 monolayers.

Figure 6: TOF-SIMS spectrum from the $\mathrm{CuSO}_{4} / \mathrm{SiO}_{2}$ sample with copper oxide and $\mathrm{SiO}_{2}$ cluster ions. Projectiles were $\mathrm{Xe}^{48+}$ with a kinetic energy of $557 \mathrm{keV}$. 


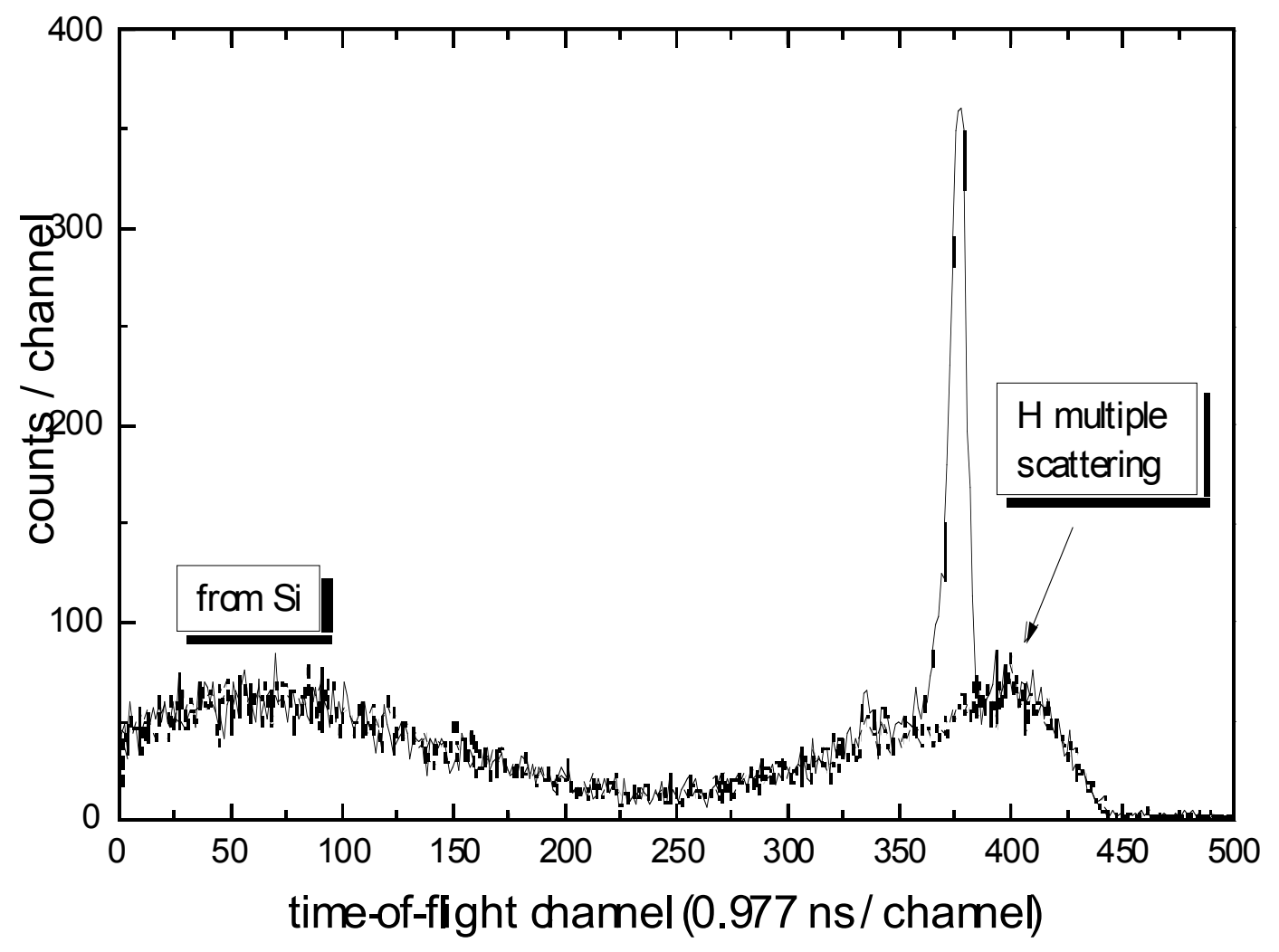




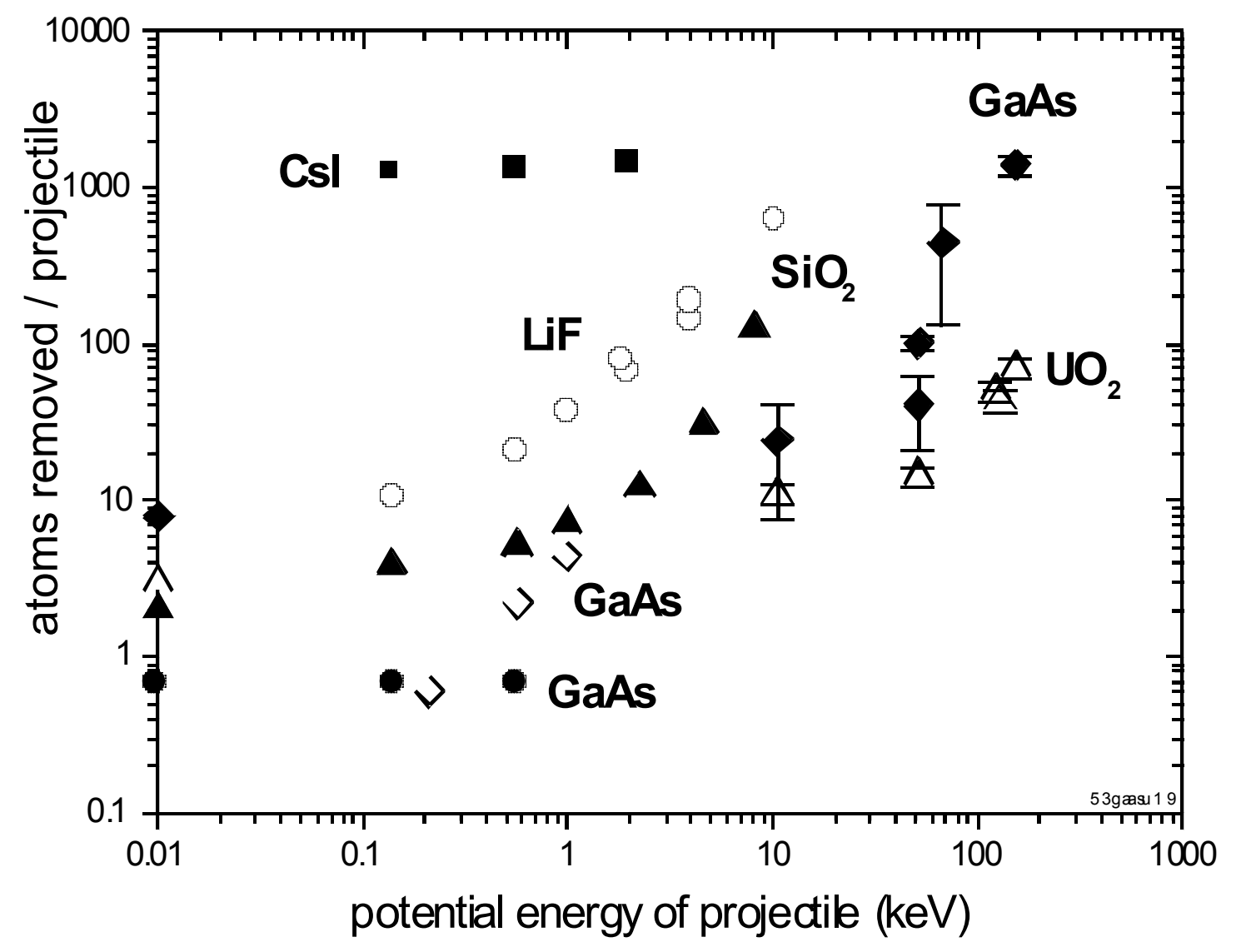




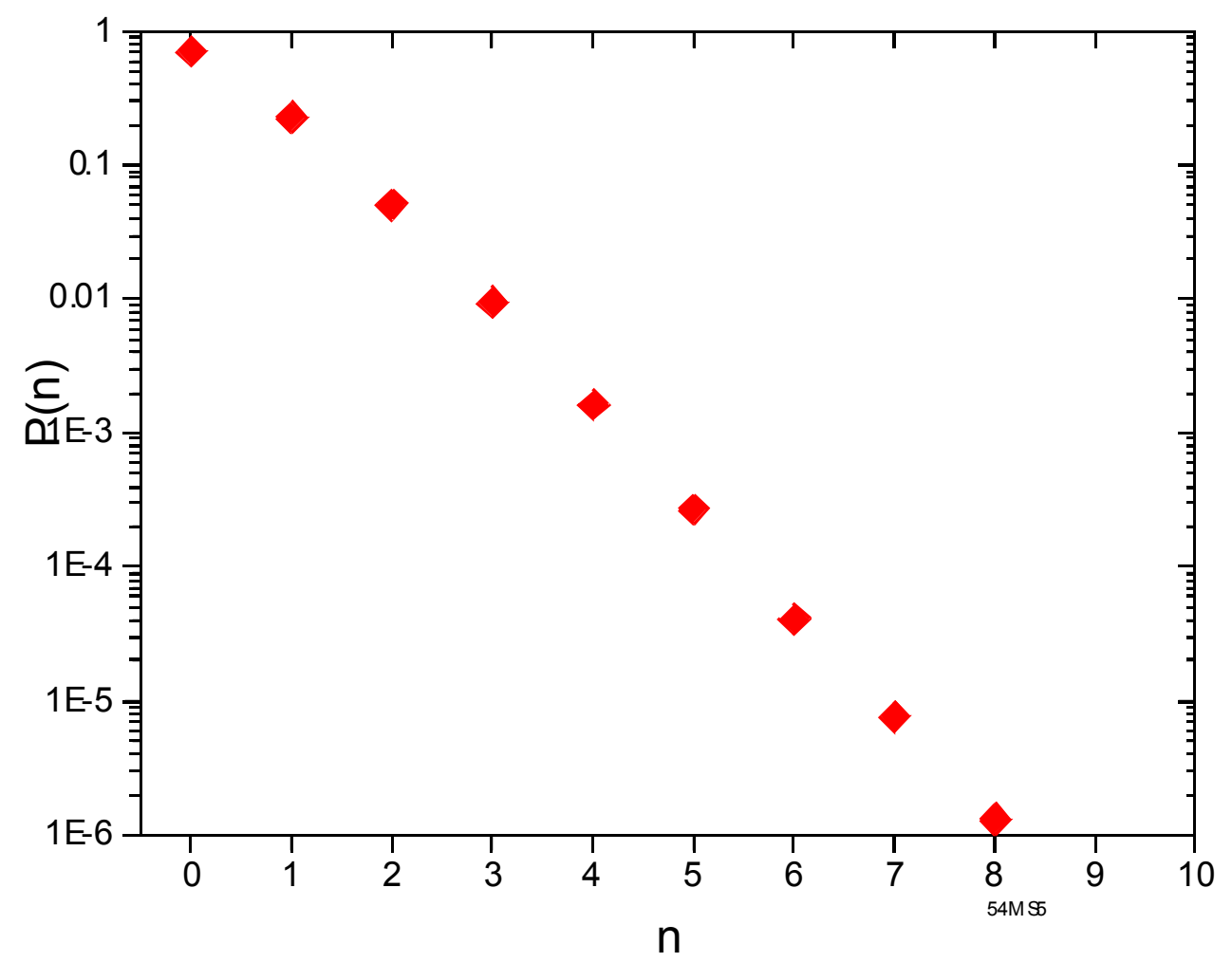




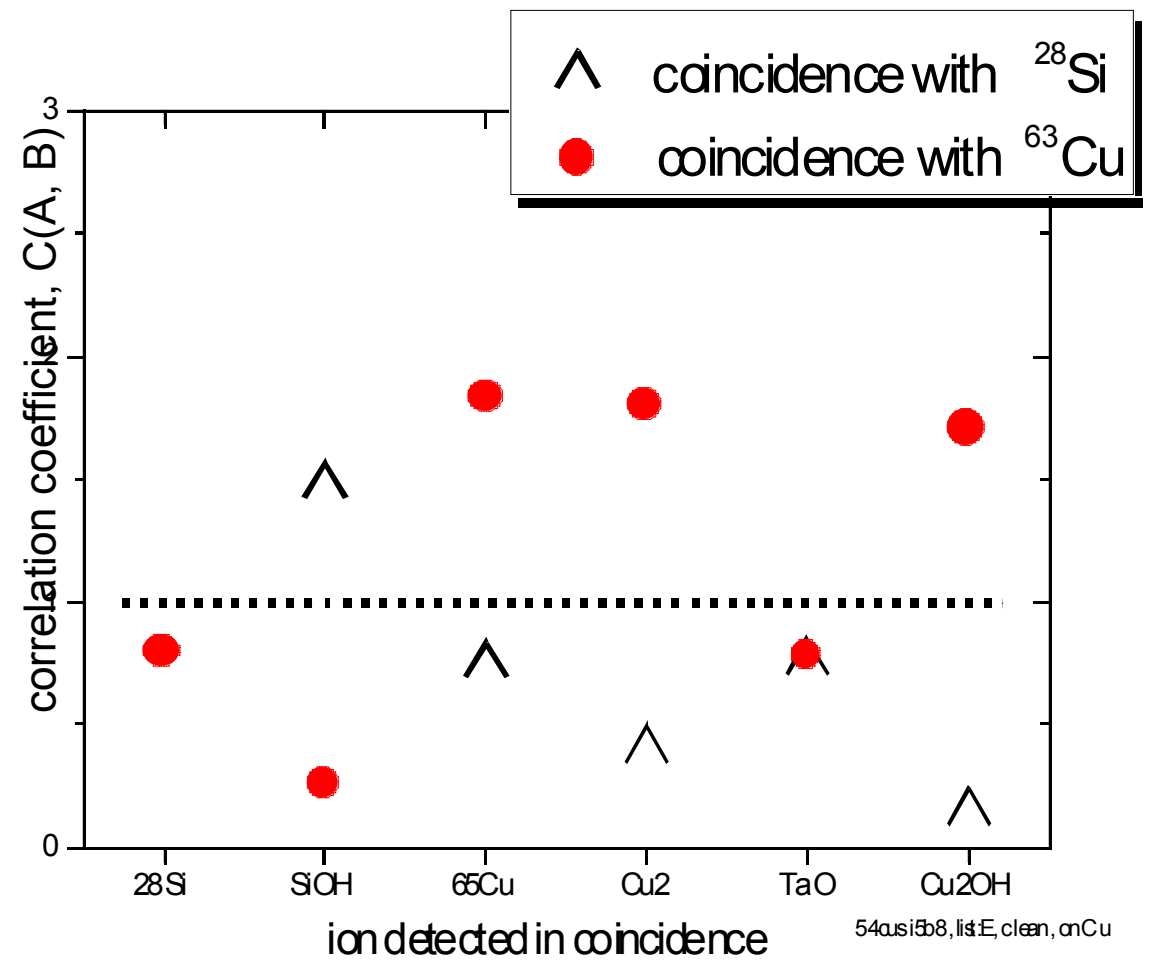




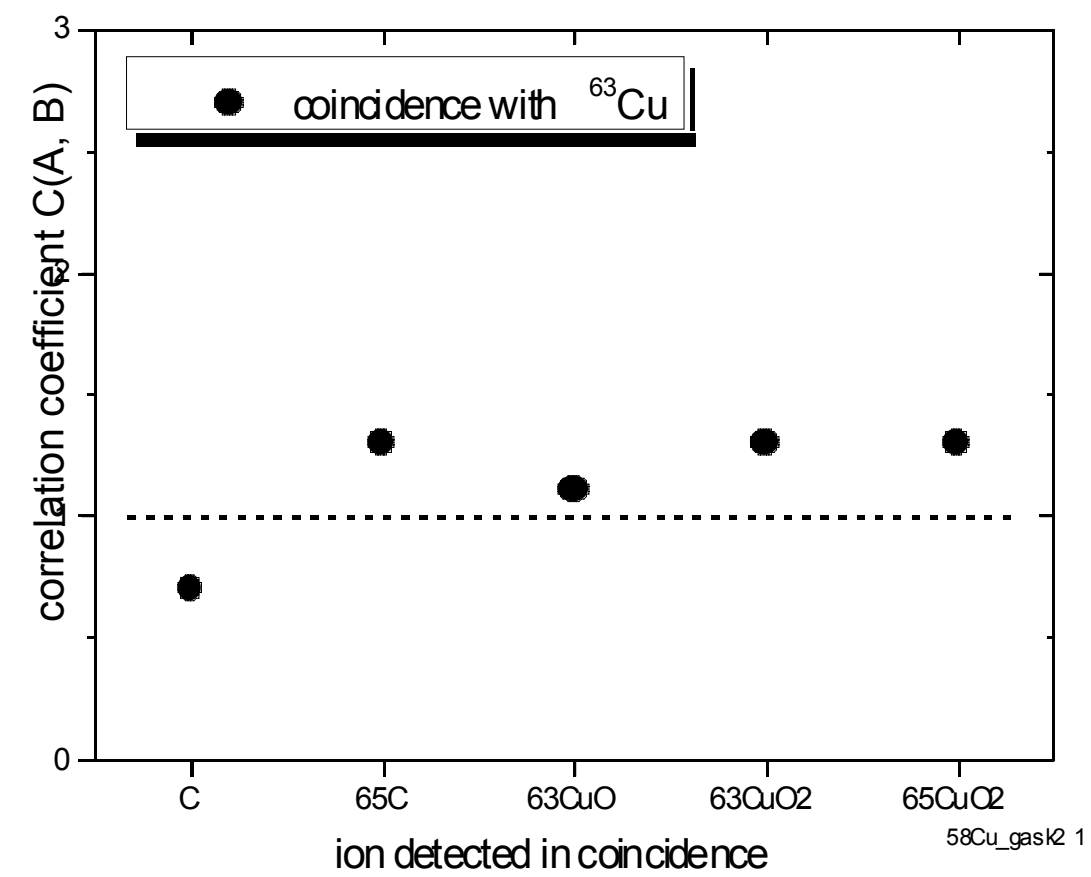




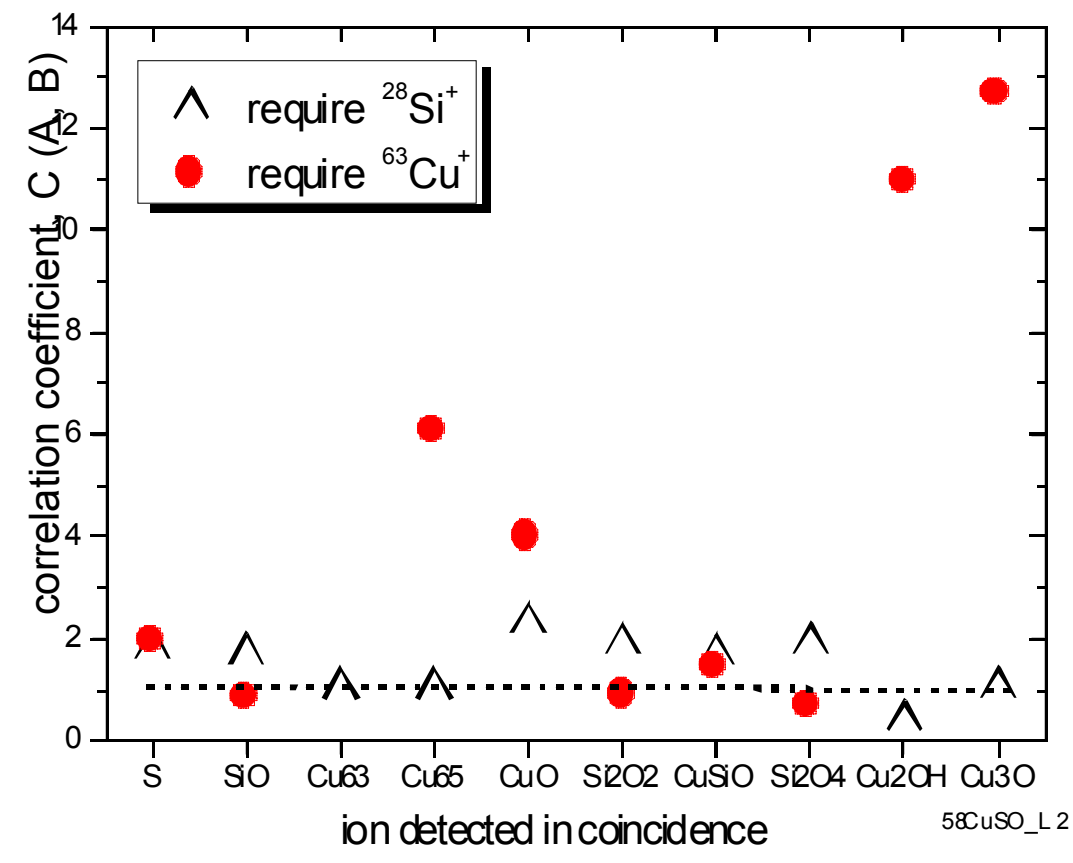




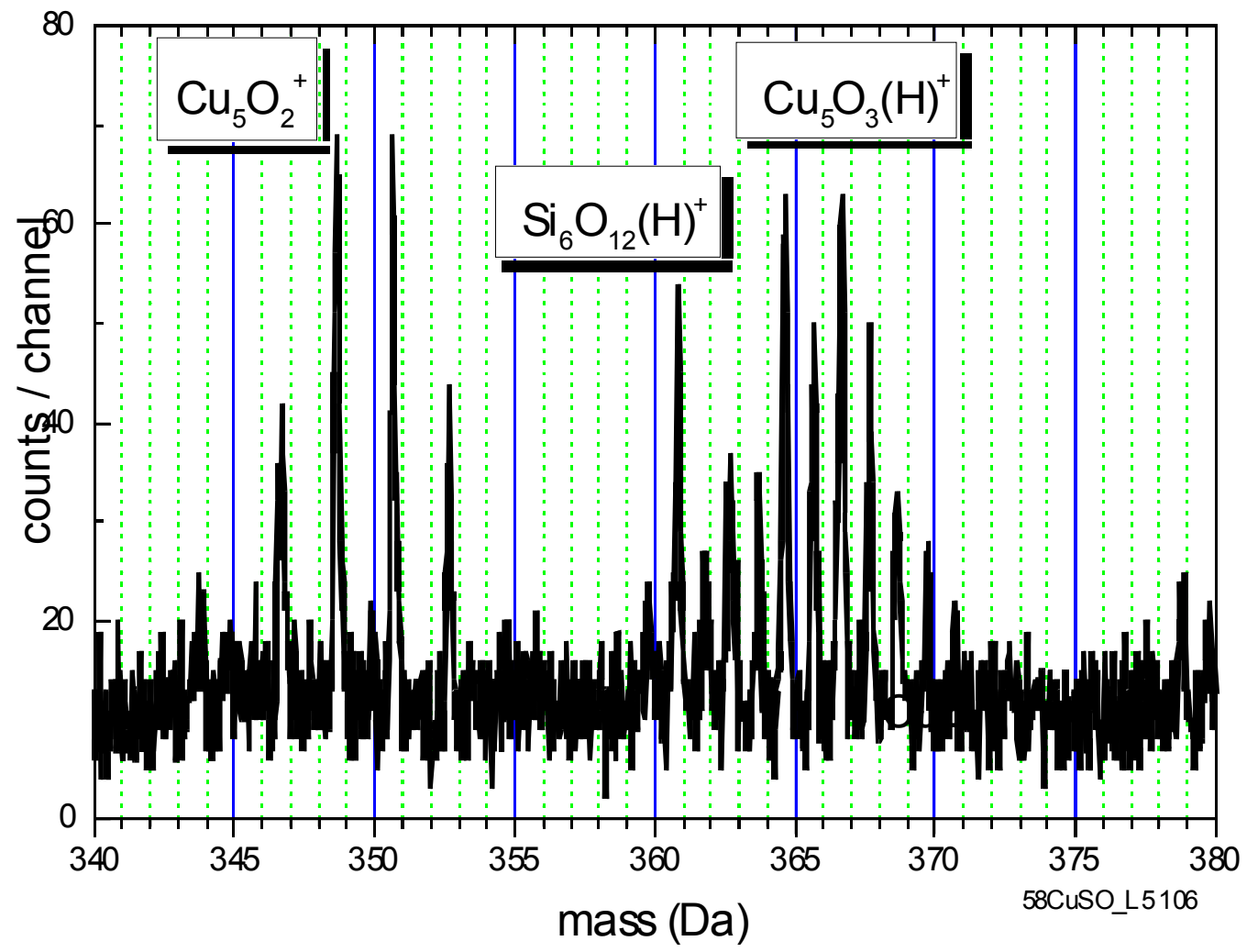

